\title{
Electrical conduction and thermodynamic properties of $\mathrm{K}_{2} \mathrm{NiP}_{2} \mathrm{O}_{7}$
}

\author{
R. Ben Said • B. Louati • K. Guidara
}

Received: 6 June 2013 /Revised: 16 July 2013 / Accepted: 3 August 2013 / Published online: 17 August 2013

(C) The Author(s) 2013. This article is published with open access at Springerlink.com

\begin{abstract}
The pyrophosphate $\mathrm{K}_{2} \mathrm{NiP}_{2} \mathrm{O}_{7}$ has been synthesized by the classic ceramic method and characterized by Xray diffraction, solid-state ${ }^{31} \mathrm{P}$ magic angle spinning (MAS) NMR, and IR and electrical impedance spectroscopy. The solid-state ${ }^{31} \mathrm{P}$ MAS NMR, performed at $121.49 \mathrm{MHz}$, shows two isotropic resonances at -17.66 and $-19.94 \mathrm{ppm}$, revealing the existence of two phosphorus environments in the structure. The electrical conductivity and dielectric properties have been investigated in the frequency and the temperature range of $200 \mathrm{~Hz}-1 \mathrm{MHz}$ and $603-728 \mathrm{~K}$, respectively. The frequency dependence of the conductivity is interpreted using the augmented Jonscher relation. The close values of activation energies obtained from the analysis of hopping frequency and dc conductivity imply that the transport is through ion hopping mechanism. The charge carrier concentration in the investigated sample has been evaluated using the Almond-West formalism and shown to be independent of temperature. Thermodynamic parameters such as the free energy of activation $\Delta F$, the enthalpy $\Delta H$, and the change in entropy $\Delta S$ have been calculated.
\end{abstract}

Keywords $\mathrm{K}_{2} \mathrm{NiP}_{2} \mathrm{O}_{7} \cdot$ Migration entropy $\cdot$ Ionic conduction $\cdot$ Enthalpy of activation for the dipolar orientation

\section{Introduction}

Despite the abundant literature references to the chemistry and structure of phosphates and their potential importance in industrial application, an important number of alkaline/divalent ion diphosphates of stoichiometry $\mathrm{A}_{2} \mathrm{BP}_{2} \mathrm{O}_{7}$ are known. In particular, $\mathrm{A}=\mathrm{K}$ materials with divalent cations $(\mathrm{Zn}, \mathrm{Pd}, \mathrm{Cd}$,

R. B. Said $(\bowtie) \cdot$ B. Louati $\cdot$ K. Guidara

Condensed Matter Laboratory, Faculty of Sciences, University of

Sfax, B.P. 1171, 3000 Sfax, Tunisia

e-mail: bensaid_rahma@hotmail.fr
Sr) were characterized [1-4]. These and other related diphosphates have awaked great interest in relation to their potential technological applications, as some of them may have magnetic and useful catalytic properties [5-7]. Besides, some of them have been proposed as cathode materials for lithium batteries $[8,9]$ and even, as nanoparticles, for decontamination and remediation of water [10].

The single-crystal structure of $\mathrm{K}_{2} \mathrm{NiP}_{2} \mathrm{O}_{7}$ is known, and the solid lattice is characterized by edge- and corner-sharing $\mathrm{PO}_{4}$ and $\mathrm{NiO}_{6}$ polyhedra. $\mathrm{K}^{+}\left(\mathrm{KO}_{x}, x=5,6\right.$, and 7) ions are found in cavities in the lattice (Fig. 1). $\mathrm{Ni}^{+}$ions are found on plans parallel to the crystallographic (100) at $x=0.42$ and $0.58 \mathrm{Ni}$ atoms are grouped as dimers with $\mathrm{Ni}-\mathrm{Ni}$ distances of 2.866 and $2.827 \AA$. Dimers are bridged by three oxygen atoms. This may be viewed as two $\mathrm{NiO}_{6}$ octahedra sharing a face and is unprecedented in ortho or pyrophosphates chemistry. The $\mathrm{P}_{2} \mathrm{O}_{7}{ }^{4-}$ groups are seen in eclipsed conformation with $\mathrm{P}-\mathrm{O}-$ $\mathrm{P}$ angles averaging $123^{\circ}$; $\mathrm{P}-\mathrm{O}$ distances vary between 1.53 and $1.56 \AA$ [11].

Our interest in the $\mathrm{K}_{2} \mathrm{NiP}_{2} \mathrm{O}_{7}$ compound is dictated by the following:

1. First, alkali transitional metal phosphates have been extensively studied owing to their wide applications as prospective materials in technology, viz. as electronic devices, solid electrolytes, sensors, solid-state laser materials, piezoelectric materials, luminescent materials, catalysts, ceramics, and magnetic materials. The $\mathrm{K}_{2} \mathrm{NiP}_{2} \mathrm{O}_{7}$ sample was used as a catalyst such as in the preparation of methyl (E)- $\alpha$-cyanocinnamate [12].

2. Second, this compound contains a magnetic atom of the transition member $\mathrm{Ni}$, which leads to antiferromagnetic ordering. Furthermore, the presence of alkaline ions $\left(\mathrm{K}^{+}\right)$ in this material can lead to an interesting multifunctional compound.

In this study we report the electrical properties of the $\mathrm{K}_{2} \mathrm{NiP}_{2} \mathrm{O}_{7}$ compound by means of impedance spectroscopy 


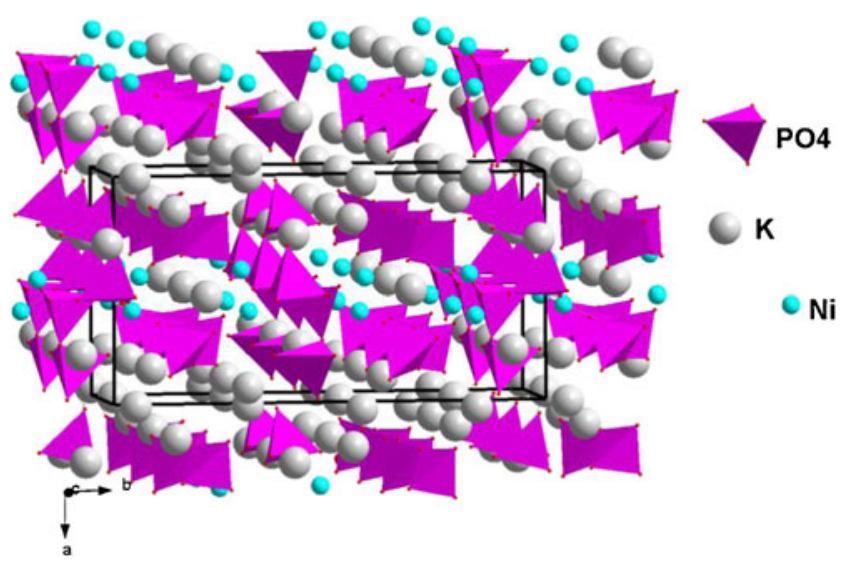

Fig. 1 Schematic representation of the $\mathrm{K}_{2} \mathrm{NiP}_{2} \mathrm{O}_{7}$ structure

and discuss the conduction mechanism in this material and its correlation with the crystallographic properties. The main aim of this work is to estimate the charge carrier parameters using the Almond-West approach and determine the values of the thermodynamic parameters of activation for the dipolar orientation.

\section{Experimental procedure}

The $\mathrm{K}_{2} \mathrm{NiP}_{2} \mathrm{O}_{7}$ ceramic was prepared by a conventional method. Stoichiometric quantities of $\mathrm{NiCO}_{3} \cdot 2 \mathrm{Ni}(\mathrm{OH})_{2} \cdot 4 \mathrm{H}_{2} \mathrm{O}$, $\mathrm{K}_{2} \mathrm{CO}_{3}$, and $\mathrm{NH}_{4} \mathrm{H}_{2} \mathrm{PO}_{4}$ with $99 \%$ purity were ground and progressively heated to $573 \mathrm{~K}$ for $16 \mathrm{~h}$ to eliminate $\mathrm{NH}_{3}, \mathrm{CO}_{2}$, and $\mathrm{H}_{2} \mathrm{O}$. The obtained product is again ground manually, pressed in pellet, and heated at $873 \mathrm{~K}$ for $8 \mathrm{~h}$.

X-ray powder diffraction pattern was recorded using a Phillips powder diffractometer operating with copper radiation $\lambda=1.54187 \AA$ over a wide range of Bragg angles $\left(5^{\circ} \leq\right.$ $\left.2 \theta \leq 60^{\circ}\right)$. Unit cell parameters of the synthesis compound have been refined by the least square method from the powder data. The infrared absorption spectrum of the crystalline powder was recorded using an FT-IR 100 PerkinElmer spectrophotometer in the $500-1,300 \mathrm{~cm}^{-1}$ range.

The ${ }^{31} \mathrm{P}$ NMR experiments were performed on a Bruker MSL 300 ( $B=7.1 \mathrm{~T})$ spectrometer working at $121.49 \mathrm{MHz}$. The powdered sample was pocketed in the rotor and allowed to rotate at speeds of 5 and $8 \mathrm{kHz}$ in a Doty magic angle spinning (MAS) probehead. Single pulse sequence program (zero Go) was used with a $\pi / 2$ pulse length of $5 \mu$ s. All chemical shifts $\delta$ are given with respect to $85 \% \mathrm{H}_{3} \mathrm{PO}_{4}$, according to the IUPAC convention, i.e., shielding corresponds to negative values. The chemical shift tensor components were obtained using Bruker Winfit software [13].

The electrical measurements were performed using a twogold-electrode configuration. The sample was made into a cylindrical pellet with a typical dimension of $8 \mathrm{~mm}$ in diameter and $0.6 \mathrm{~mm}$ in thickness pressed at a pressure of $5,000 \mathrm{~kg} \mathrm{~cm}^{-2}$. Electrical impedances were measured in the frequency range from $200 \mathrm{~Hz}$ to $1 \mathrm{MHz}$ with the TEGAM 3550 ALF automatic bridge monitored by a microcomputer. Measurements were carried out at temperatures from 603 to $728 \mathrm{~K}$.

\section{Results and discussions}

Crystalline parameters

The room temperature XRD pattern of $\mathrm{K}_{2} \mathrm{NiP}_{2} \mathrm{O}_{7}$ is shown in Fig. 2. The formation of pure-phase $\mathrm{K}_{2} \mathrm{NiP}_{2} \mathrm{O}_{7}$ without secondary phases has been confirmed. All the reflection peaks were indexed in the monoclinic system with the space group $P 2_{1}$. The refined lattice parameters are $a=9.228(1) \AA, b=17.555(9)$ $\AA, c=8.335(1) \AA, \beta=91.48(2)^{\circ}$, and $V=1349.886(4) \AA^{3}$ which are in good agreement with the literature [11].

Infrared absorption spectroscopy

Figure 3 shows the infrared spectrum of the $\mathrm{K}_{2} \mathrm{NiP}_{2} \mathrm{O}_{7}$ sample recorded at room temperature; their band assignments are given in Table 1. The assignment of the bands was effectuated by comparison with similar compounds [14-16]. The principal modes are assigned in the internal modes of the $\mathrm{P}_{2} \mathrm{O}_{7}$ group: One can observe three groups of bands:

1. The first is located in the region $1,185-1,162 \mathrm{~cm}^{-1}$ which is attributed to the antisymmetric stretching modes of vibration $v_{\mathrm{a}}\left(\mathrm{PO}_{3}\right)$.

2. The second is in the range $1,093-1,053 \mathrm{~cm}^{-1}$ which corresponds to the symmetric stretching modes of vibration $v_{\mathrm{s}}\left(\mathrm{PO}_{3}\right)$.

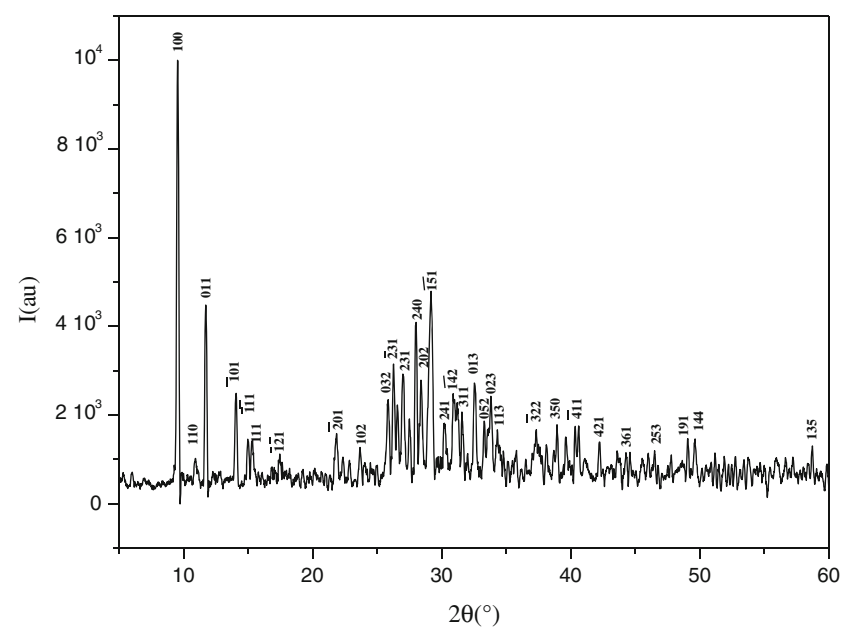

Fig. 2 X-ray diffraction pattern of the investigated $\mathrm{K}_{2} \mathrm{NiP}_{2} \mathrm{O}_{7}$ compound prepared by solid-state reaction technique 


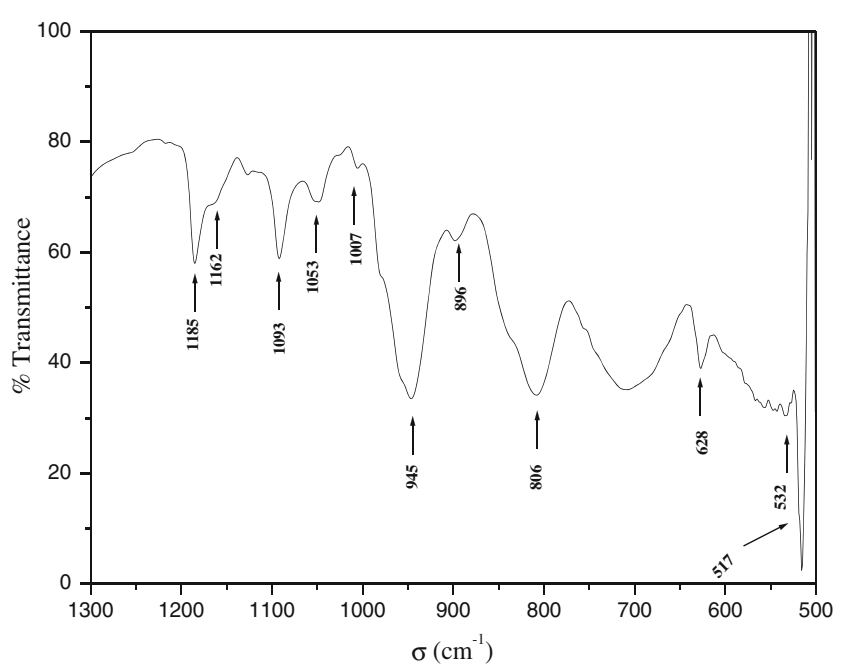

Fig. 3 Infrared spectra of $\mathrm{K}_{2} \mathrm{NiP}_{2} \mathrm{O}_{7}$ recorded at room temperature

3. The third is observed between 945 and $806 \mathrm{~cm}^{-1}$ which is assigned to the antisymmetric stretching mode of (POP).

In addition to these bands, a smaller band observed at $1,007 \mathrm{~cm}^{-1}$ is attributed to the antisymmetric stretching of the $\left(\mathrm{PO}_{3}\right)$ group. Another band, assigned to antisymmetric (POP) stretching, arised near $628 \mathrm{~cm}^{-1}$. Two bands located at 532 and $517 \mathrm{~cm}^{-1}$ are attributed to $\delta_{\mathrm{a}}\left(\mathrm{PO}_{3}\right)$ deformation modes.

Note that one of the most interesting aspects of the IR study is the ability to obtain direct information about the configuration of the $\mathrm{P}-\mathrm{O}-\mathrm{P}$ bridges. The symmetric POP stretching mode $\delta$ (POP) confirms the presence of the diphosphate group in the compound.

\section{${ }^{31}$ P NMR MAS study}

The ${ }^{31} \mathrm{P}$ spectrum for a sample rotating at magic angle (MAS) with two frequencies $v=5$ and $8 \mathrm{kHz}$ and the simulated isotropic bands are shown in Fig. 4a, b, respectively.

Table 1 Assignment of IR bands for $\mathrm{K}_{2} \mathrm{NiP}_{2} \mathrm{O}_{7}$
Spinning the sample at low and high velocities $(\nu=5$ and $8 \mathrm{kHz}$ ) allows us to assign two isotropic peaks $\mathrm{A}$ and $\mathrm{B}$ at positions independent of the spinning rate, -17.66 and $-19.94 \mathrm{ppm}$, in the proportions 39.91 and $60.09 \%$, respectively, revealing the presence of two phosphorus environments in the structure. This result apparently disagrees with the structural evidences. In fact, NMR investigation reveals the presence of two phosphorus sites, but four distinct sets of pairs of $\mathrm{PO}_{4}$ units are found in the primitive cell by X-ray investigation [11].

A careful study of the crystallographic data shows that five among the eight phosphorus atoms have an average distance $<\mathrm{P}-\mathrm{O}>$ equal to $1.53 \AA$ and the three other atoms are characterized by $<\mathrm{P}-\mathrm{O}>$ equal to $1.55 \AA$. In the literature various studies show that the isotropic chemical shift for the $\mathrm{Q}_{1}$ band $\delta_{\text {iso }}$ is average distance $<\mathrm{P}-\mathrm{O}>$ dependent. A linear relationship between $\delta_{\text {iso }}$ and $<\mathrm{P}-\mathrm{O}>$ has been proposed [17]:

$\delta_{\text {iso }}=A *<\mathrm{P}-\mathrm{O}>-B$

where $A \approx 780 \mathrm{ppm} \AA^{-1}$ and $1,213 \mathrm{ppm} \lesssim B \lesssim 1.224 \mathrm{ppm}$.

This result can explain the existence of only two phosphorus peaks in the NMR spectra. According to the previous equation, we will consider that the highest $\delta_{\text {iso }}$ corresponds to the largest $<\mathrm{P}-\mathrm{O}>$. Therefore, $A$ with the highest $\delta_{\text {iso }}(-17.66)$ should correspond to the three phosphorus atoms having the largest $<\mathrm{P}-\mathrm{O}>(1.55 \AA)$ and the proportion $39.91 \%$.

The chemical shift tensors for the two types of $\mathrm{PO}_{4}$ groups were obtained by an iterative procedure using the Dmfit program [13]. Table 2 summarizes these results, under the conventional forms $\delta_{11}, \delta_{22}$, and $\delta_{33}$ as well as under the more useful parameters (the isotropic chemical shift $\delta_{\text {iso }}$, the chemical shift anisotropy $\delta_{\mathrm{CS}}$, and the asymmetry parameter $\eta[18]$ ).

$\delta_{11}, \delta_{22}$, and $\delta_{33}$ are the diagonal terms of the chemical shift tensor expressed in the principal axis system, according to

$\delta_{11}>\delta_{22}>\delta_{33}$

Or

$\delta_{11}<\delta_{22}<\delta_{33}$

with the convention that

$\left|\delta_{11}-\delta_{22}\right|<\left|\delta_{22}-\delta_{33}\right|$,

$\delta_{\text {iso }}=\left(\delta_{11}+\delta_{22}+\delta_{33}\right) / 3$,

$\delta_{C S}=\delta_{33}-\delta_{i s o}$,

And

$\eta=\left(\delta_{22}-\delta_{11}\right) /\left(\delta_{33}-\delta_{\text {iso }}\right)$. 

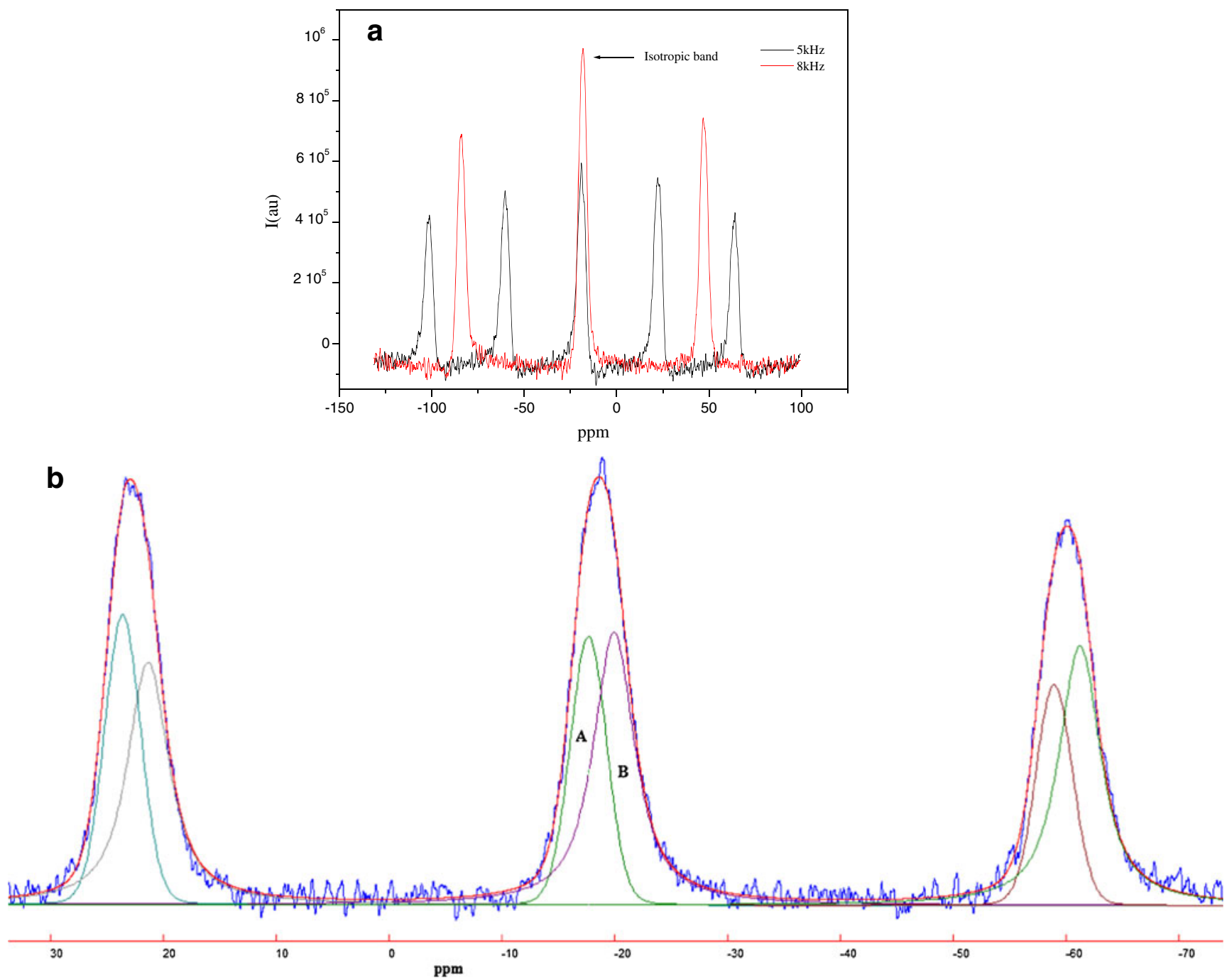

Fig. 4 a ${ }^{31}$ P NMR spectrum for a sample rotating at magic angle ( $v=5$ and $\left.8 \mathrm{kHz}\right)$ with $\mathbf{b}$ simulated isotropic and spinning bands. Peak A green color, peak B blue color

The chemical shift tensor orientation is depicted in Fig. 5, where the axes have been renumbered in agreement with the above conventions.

\section{Electrical properties}

Electrical conductivity in materials is due to the ordered motion of weakly bound charged particles under the influence of an electric field, and it is a thermally activated process. It is one of the significant properties of materials to be characterized depending on the nature of charge carriers dominating the conduction process such as electrons/holes or cations/anions. The complex impedance spectra of $\mathrm{K}_{2} \mathrm{NiP}_{2} \mathrm{O}_{7}$ for some representative temperatures are shown in Fig. 6. They are characterized by the appearance of semicircle arcs with a tail at low frequency. We propose an equivalent circuit formed by a series combination of two cellules: the first consists of a parallel combination of resistance $(R)$, capacitance $\left(C_{1}\right)$, and fractal capacitance (CPE), whereas the second consists of another capacitance $\left(C_{2}\right)$ (Fig. 6 inset). This circuit shows that the measured electrical properties correspond to the bulk response of the samples with little evidence for significant grain

Table $2{ }^{31} \mathrm{P}$ NMR parameters

\begin{tabular}{llllllllll}
\hline Peak & Percent & $\begin{array}{l}\delta_{\text {iso }} \\
\mathrm{ppm}\end{array}$ & $\begin{array}{l}\delta_{\mathrm{CS}} \\
\mathrm{ppm}\end{array}$ & $\begin{array}{l}\text { FWHM } \\
\mathrm{ppm}\end{array}$ & $\eta$ & $X(G / L)$ & $\begin{array}{l}\delta_{11} \\
\mathrm{ppm}\end{array}$ & $\begin{array}{l}\delta_{22} \\
\mathrm{ppm}\end{array}$ & $\begin{array}{l}\delta_{33} \\
\mathrm{ppm}\end{array}$ \\
\hline $\mathrm{A}$ & 39.91 & -17.66 & -239.1 & 3.83 & 0.7 & 0.93 & 231.5 & 26.3 & -310.8 \\
$\mathrm{~B}$ & 60.09 & -19.94 & 313.7 & 4.39 & 0.95 & 0.16 & -325.8 & -27.7 & 293.8 \\
\hline
\end{tabular}




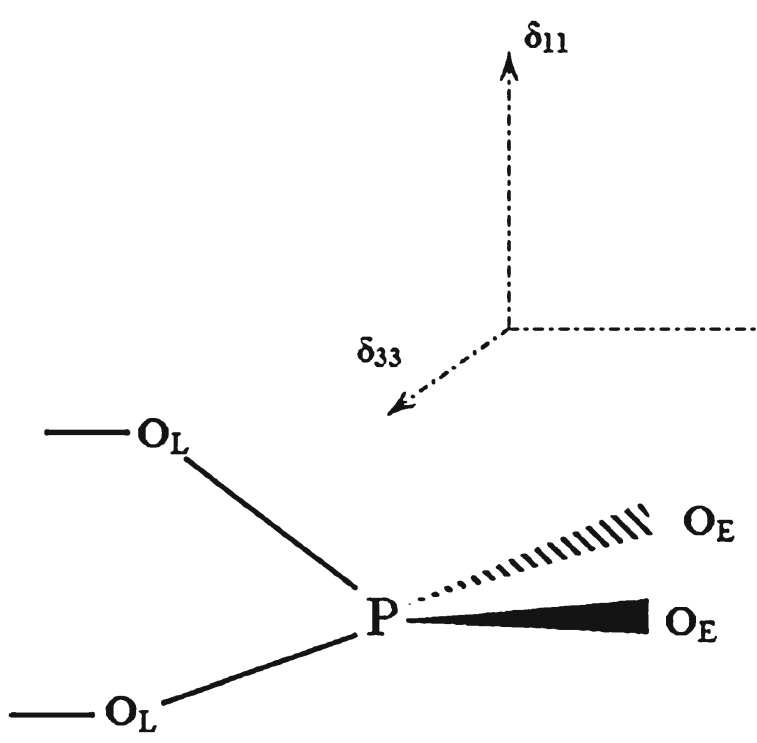

Fig. 5 Chemical shift tensor orientation, where $(L)$ and $(E)$ indicate linkage and external oxygen atoms, respectively

boundary impedances [19]. The impedance of the constant phase element (capacity of the fractal interface CPE) is [20]

$Z_{C P E}=\frac{1}{Q(i \omega)^{\alpha}}$

where $Q$ indicates the value of the capacitance of the CPE element and $\alpha$ is the fractal exponent. Further, the previous equation shows that as $\alpha \rightarrow 1, Z_{\mathrm{CPE}} \rightarrow 1 / i Q \omega$, involving a pure capacitance, and as $\alpha \rightarrow 0, Z_{\mathrm{CPE}} \rightarrow 1 / Q$, involving a pure resistance.

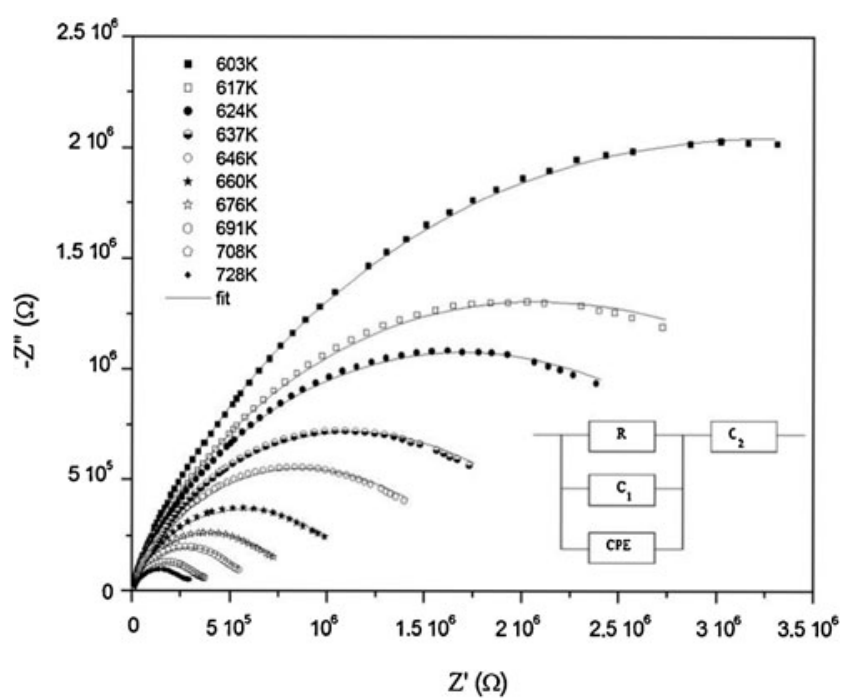

Fig. 6 The Cole-Cole plot of the impedance of $\mathrm{K}_{2} \mathrm{NiP}_{2} \mathrm{O}_{7}$ at different temperatures
The expressions of $|Z|$ and phase $\theta$ related to the equivalent circuit are obtained from the real $\left(Z^{\prime}\right)$ and the imaginary $\left(Z^{\prime \prime}\right)$ parts of the complex impedance:

$|Z|=\sqrt{Z^{\prime 2}+Z^{\prime \prime 2}}$

and

$\theta=\tan ^{-1}\left(\frac{Z^{\prime \prime}}{Z^{\prime}}\right)$

where $Z^{\prime}$ and $Z^{\prime \prime}$ can be written as

$$
\begin{aligned}
Z^{\prime}= & \frac{R^{-1}+Q \omega^{\alpha} \cos \left(\frac{\alpha \pi}{2}\right)}{\left(R^{-1}+Q \omega^{\alpha} \cos \left(\frac{\alpha \pi}{2}\right)\right)^{2}+\left(C_{1} \omega+Q \omega^{\alpha} \sin \left(\frac{\alpha \pi}{2}\right)\right)^{2}} \\
-Z^{\prime \prime}= & \frac{C_{1} \omega+Q \omega^{\alpha} \sin \left(\frac{\alpha \pi}{2}\right)}{\left(R^{-1}+Q \omega^{\alpha} \cos \left(\frac{\alpha \pi}{2}\right)\right)^{2}+\left(C_{1} \omega+Q \omega^{\alpha} \sin \left(\frac{\alpha \pi}{2}\right)\right)^{2}} \\
& +\frac{1}{C_{2} \omega} .
\end{aligned}
$$

Figures 7 and 8 show the variation of the impedance component $|Z|$ and $\theta$ versus angular frequency; those plots show a good agreement between simulated and experimental data. The extracted values of capacitance $\left(C_{1}\right)$ are in the range of picofarads, implying that the single semicircle response is from grain interiors. The values of $\alpha$ are about 0.7 , revealing the weakness interaction between localized sites. The magnitude of dc conductivity $\sigma_{\mathrm{dc}}$ can be calculated using the following relation:

$\sigma_{d c}=\frac{e}{S R}$

where $S$ is the electrolyte-electrode contact area, $e$ is the thickness of the pellet, and $R$ is the bulk resistance extracted from the fit of $|Z|$ and $\theta$ using Eqs. (11) and (12). The temperature dependence of the conductivity is presented in Fig. 9 in the form of $\operatorname{Ln}\left(\sigma_{\mathrm{dc}} T\right)$ versus reciprocal temperature. This plot indicates an increase in conductivity with rise in temperature. This type of temperature dependence indicates that the electrical conduction in the sample is a thermally activated transport process governed by an Arrhenius-type relation: $\sigma_{\mathrm{dc}} T=A \exp \left(-E_{\mathrm{dc}} / k T\right)$ where $E_{\mathrm{dc}}=1 \pm 0.05 \mathrm{eV}$ is the dc activation energy and $A=2.79 \times 10^{3} \Omega^{-1} \mathrm{~cm}^{-1} \mathrm{~K}$ is the conductivity pre-exponential factor.

\section{AC conductivity}

The frequency-dependent conductivity of inorganic glasses, polymers, doped semiconductors, and ionic conductors 
Fig. 7 Variation of $|Z|$ as a function of angular frequency at different temperatures and angular frequency dependence of the imaginary part $M^{\prime \prime}$ of complex modulus at $728 \mathrm{~K}$ (inset)

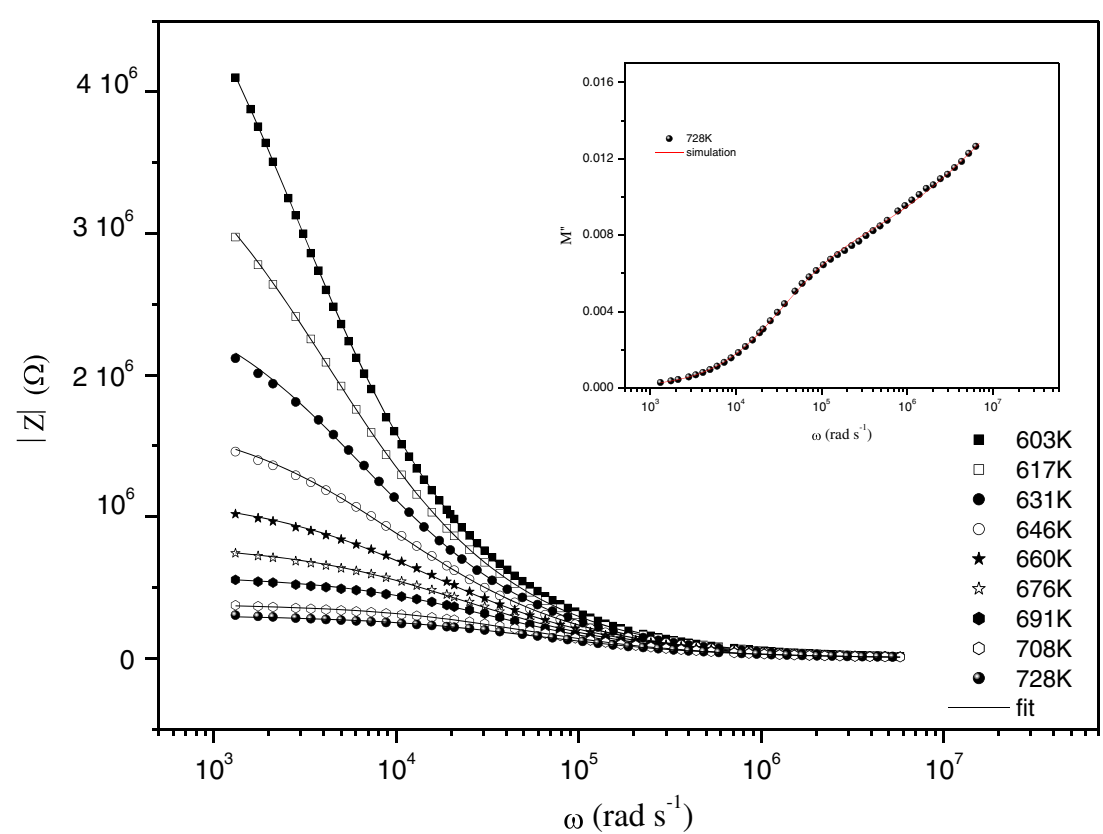

exhibits universality, and their behavior is scaled to a master curve [21-23]. The angular frequency-dependent conductivity spectra are shown in Fig. 10. The curves display a lowfrequency plateau and high-frequency dispersive regions. Angular frequency-dependent conductivity is well described by the known augmented Jonscher relation as [24]

$\sigma_{a c}(\omega)=\sigma_{d c}+A \omega^{s}+B \omega$

where $\sigma_{\mathrm{dc}}$ is the dc conductivity, $A$ is thermally activated, $B$ involves only small temperature dependence, and $s$ is an exponent function of temperature and frequency and is related

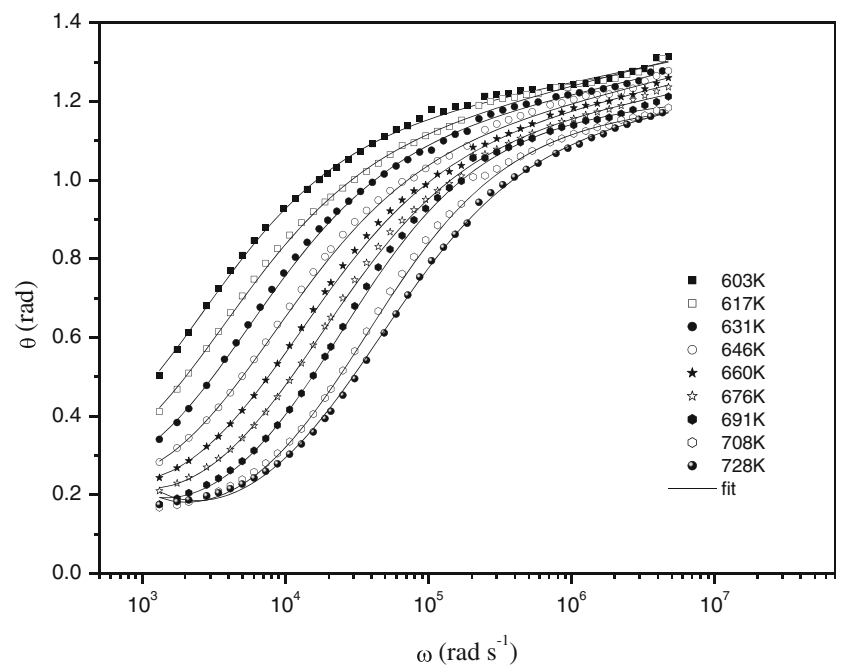

Fig. 8 Variation of the argument part $\theta$ of impedance $(Z)$ as a function of angular frequency at different temperatures to the degree of correlation among moving ions [25]. Two terms of the previous equation are denoted as, namely, universal dielectric response (UDR), in general, universal dynamic response, and nearly constant loss (NCL), respectively. These two additive terms correspond to different processes happening in the material. The power-law frequencydependent UDR term originates from the hopping of the carriers with interactions of the inherent defects or disorder in the material, whereas the linear frequency-dependent NCL term is modeled to originate from rocking motions in an asymmetric double-well potential and electrical loss occurring during the time regime while the ions are confined to the

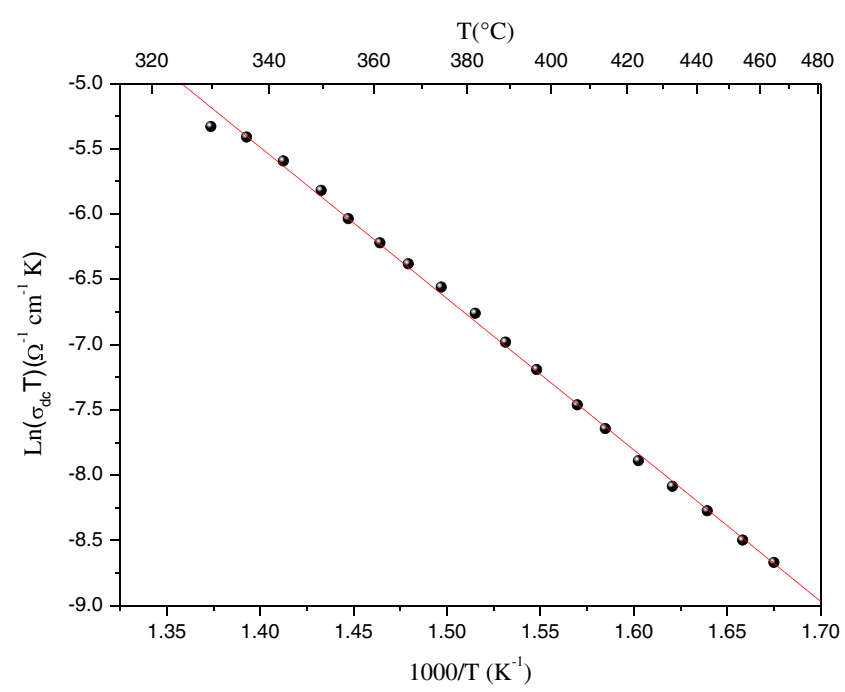

Fig. 9 Temperature dependence of $\sigma_{\mathrm{dc}}$ versus 1000/T 


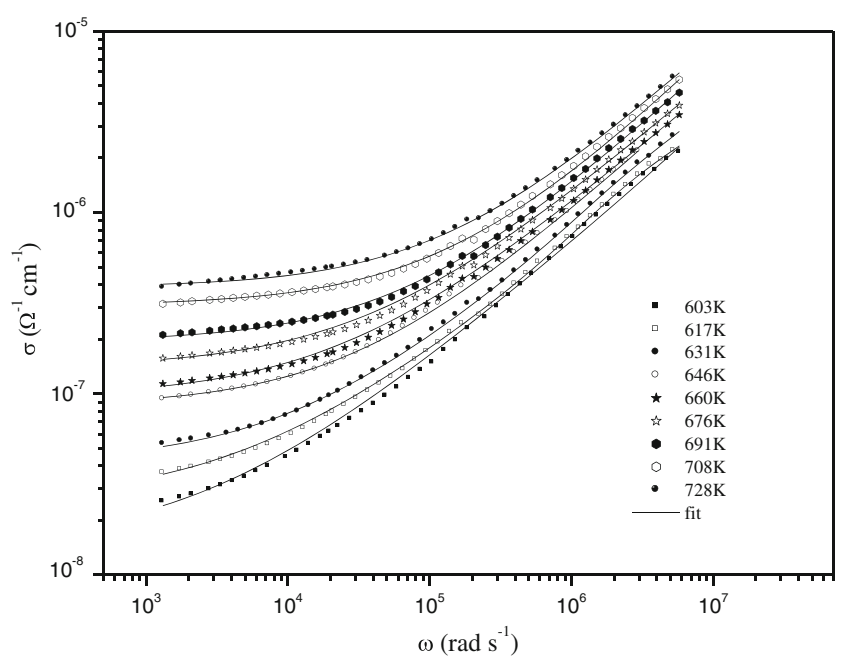

Fig. 10 Angular frequency dependence of the ac conductivity at various temperatures

potential energy minimum [24]. UDR and NCL terms are further categorized to occur in the high-temperature/low-frequency and the low-temperature/high-frequency regimes, respectively [25].

The crossover frequency from dc to the dispersive region of the ac conductivity is known as hopping frequency, $\omega_{\mathrm{h}}$, and it can be calculated directly from ac conductivity data using the formula [26]

$\omega_{\mathrm{h}}=\left(\frac{\sigma_{d c}}{A}\right)^{1 / s}$

In the past few years, different scaling models have been proposed [27-30]. Among these models, we indicated the Ghosh model:

$\frac{\sigma_{a c}(\omega)}{\sigma_{d c}}=f\left(\frac{\omega}{\omega_{\mathrm{h}}}\right)$

Figure 11 shows the conductivity plots of the $\mathrm{K}_{2} \mathrm{NiP}_{2} \mathrm{O}_{7}$ sample which are scaled at different temperatures. In this scaling process, the ac conductivity axis is scaled by $\sigma_{\mathrm{dc}}$ and the frequency axis by $\omega_{\mathrm{h}}, \sigma_{\mathrm{dc}}$ being a parameter obtained from the fit of the conductivity as a function of angular frequency. Scaling the conductivity spectra in this way at different temperatures merges on a single curve which implies that the relaxation dynamics of charge carriers is independent of temperature. In order to examine the temperature and frequency dependence of ac conductivity, we report in Fig. 12 the temperature dependence of $\sigma_{\mathrm{ac}}$ at a fixed frequency. The nature variation of $\sigma_{\mathrm{ac}}$ over a wide temperature range supports the thermally activated transport of properties of the materials obeying an Arrhenius relation: $\sigma_{\mathrm{ac}} T=B \exp \left(-E_{\mathrm{ac}} / k T\right)$. It is observed that the ac conductivity of the material increases with rise in temperature and shows the negative temperature coefficient of resistance behavior. The activation energy, $E_{\mathrm{ac}}$,

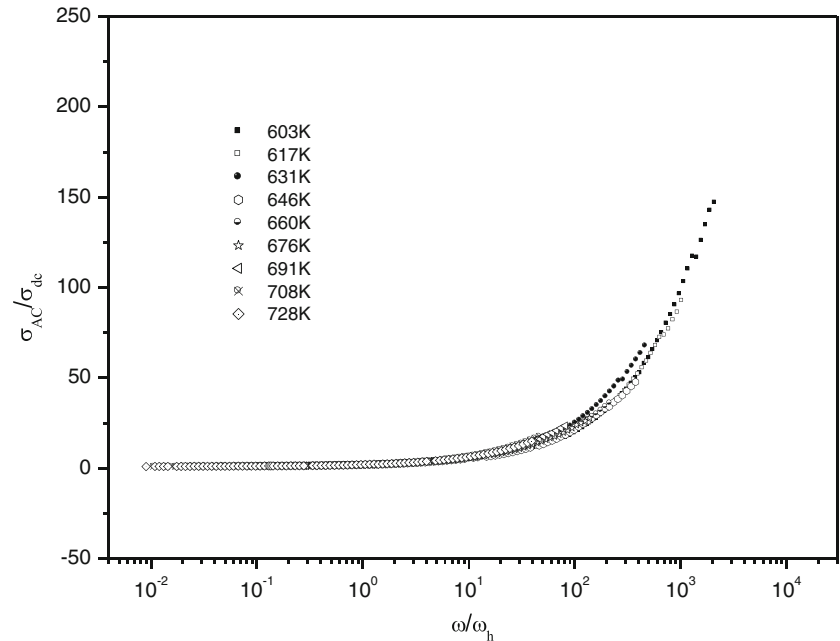

Fig. 11 Plot of $\left(\sigma_{\mathrm{ac}} / \sigma_{\mathrm{dc}}\right)$ versus $\left(\omega / \omega_{\mathrm{h}}\right)$ at different temperatures

of $\sigma_{\mathrm{ac}}$ conductivity for a selected frequency was determined from the slope of $\log \sigma_{\mathrm{ac}}(\omega) T$ versus 1,000/T.

The frequency variation of the obtained activation energy, $E_{\text {ac }}$, is shown in Fig. 13. It is clear that $E_{\mathrm{ac}}$ remains constant at low frequency and decreases at high frequency with increasing frequency. The activation energy involves the activation energies of formation of the vacant sites and migration of the mobile carriers.

Figure 14 shows the temperature dependence of the hopping frequency calculated from Eq. (15); an Arrhenius type behavior is shown. The activation energy calculated from the slope of $\operatorname{Ln}\left(\omega_{\mathrm{h}}\right)$ versus $1,000 / T$ is found to be $E_{\mathrm{hop}}=1.07 \pm$ $0.05 \mathrm{eV}$. This value is very close to that determined above from dc conductivity $E_{\mathrm{dc}}=1 \pm 0.05 \mathrm{eV}$, implying that the mobility of the charge carrier is due to a hopping mechanism in the investigated material.

Inside the crystalline-phase $\mathrm{K}_{2} \mathrm{NiP}_{2} \mathrm{O}_{7}, \mathrm{~K}^{+}$ions are located in cavities along the $[0,0,1]$ axis which is formed by edge-

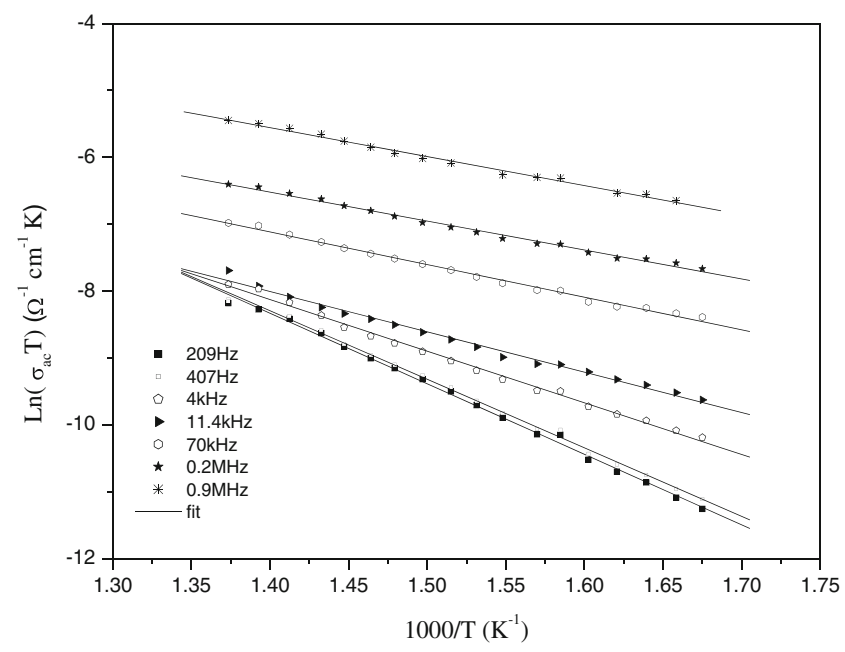

Fig. 12 Plot of ac conductivity versus 1000/T at different frequencies 


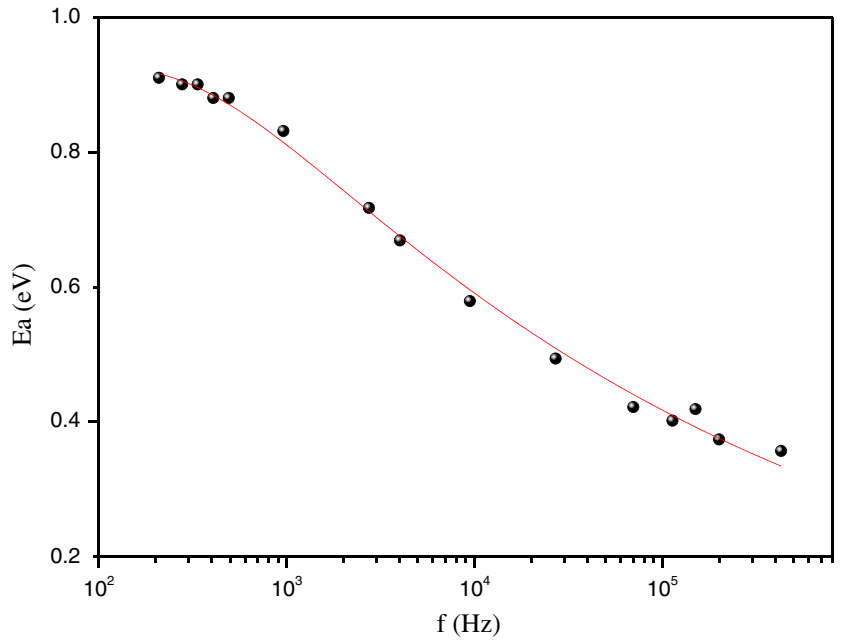

Fig. 13 Frequency dependence of ac activation energy

and corner-sharing $\mathrm{PO}_{4}$ and $\mathrm{NiO}_{6}$ polyhedra (Fig. 1). We can assume that inside the $\mathrm{K}_{2} \mathrm{NiP}_{2} \mathrm{O}_{7}$, the electrical transport is due to $\mathrm{K}^{+}$cation displacement along the $[0,0,1]$ lattices located between $\mathrm{P}_{2} \mathrm{O}_{7}$ groups and $\mathrm{NiO}_{6}$ octahedra.

In hopping transport, we can use the relationship between the dc conductivity $\sigma_{\mathrm{dc}}$ and the hopping frequency $\omega_{\mathrm{h}}[31]$ :

$\sigma_{d c}=\left(\frac{N_{\mathrm{c}} e^{2} r_{\mathrm{h}}^{2}}{12 \pi k T}\right) \omega_{\mathrm{h}}$

where $r_{\mathrm{h}}$ is the hopping distance $\left(r_{\mathrm{h}}=\mathrm{K}-\mathrm{K}\right.$ distances, which is found to be $8.319 \AA$ ) and $N_{\mathrm{c}}$ is the number of effective charge carriers. According to the previous equation, the temperature dependence of $N_{\mathrm{c}}$ is shown in Fig. 15. It is clear that $N_{\mathrm{c}}$ varies slightly depending on the temperature, and it can be

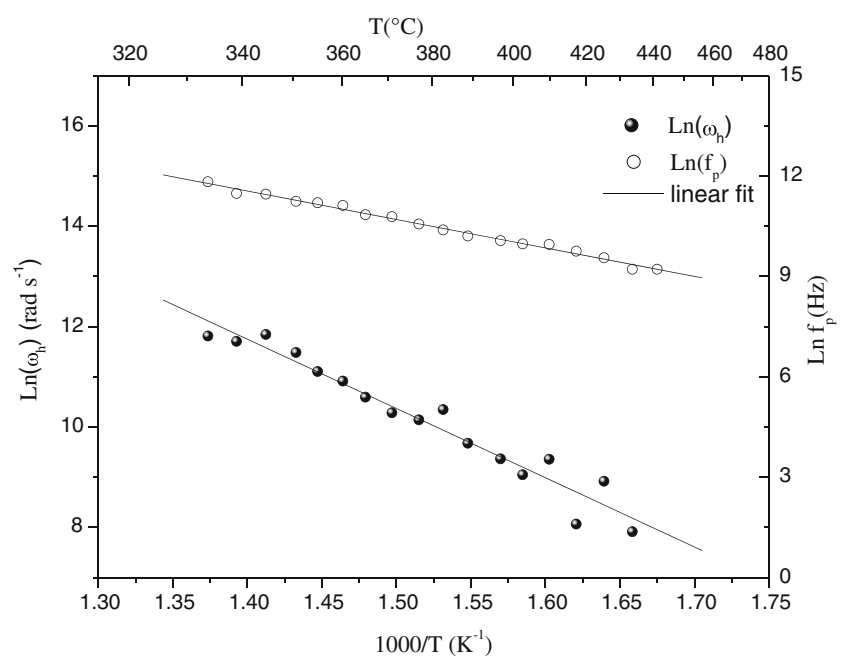

Fig. 14 Temperature dependence of the hopping frequency $\omega_{\mathrm{h}}$ and the relaxation frequency $f_{\mathrm{p}}$ considered as a constant with a value of $6.85 \times 10^{27} \pm 0.3 \times$ $10^{27} \mathrm{~m}^{-3}$. A comparison between the number density of $\mathrm{K}$ sites $\left(N_{\mathrm{k}}=1.188 \times 10^{28} \mathrm{~m}^{-3}\right)$ and the number of effective charge carriers shows that $57.65 \%$ of $\mathrm{K}^{+}$ions are responsible for the conduction in this material.

The charge carrier mobility $\mu$ can be obtained using Eq. (18):

$\mu=\frac{\sigma_{d c}}{e N_{\mathrm{c}}}$

The temperature dependence of $\mu$ is presented in Fig. 16 in the form of $\operatorname{Ln}(\mu)$ versus 1000/T. An Arrhenius-type behavior, $\mu=B \exp \left(-E_{\mu} / k T\right)$, is shown. It is observed that mobility increases with increasing temperature; the activation energy $E_{\mu}$ obtained from this plot is about $1.1 \pm 0.05 \mathrm{eV}$. This value is comparable to that deduced from the hopping frequency.

According to Eq. (14) and [32], the ac conductivity can be rewritten as follows:

$$
\begin{aligned}
\sigma_{a c}(\omega, T)= & {\left[\frac{e^{2} r_{\mathrm{h}}^{2}}{6 k T} N(T) \omega_{\mathrm{e}} \exp \left(\frac{-E_{\mu}}{k T}\right)\right] } \\
& \times\left[1+\left(\frac{\omega}{\omega_{\mathrm{e}}} \exp \left(\frac{-E_{\mu}}{k T}\right)\right)^{s}\right]+B \omega .
\end{aligned}
$$

Almond and West have shown that the ion hopping rate $\omega_{\mathrm{h}}$ $\left(\omega_{\mathrm{h}}=2 \pi v_{\mathrm{h}}\right)$ can be described by the following equation [33]:

$\omega_{\mathrm{h}}=\omega_{\mathrm{e}} \exp \left(\frac{-E_{\mu}}{k T}\right)$

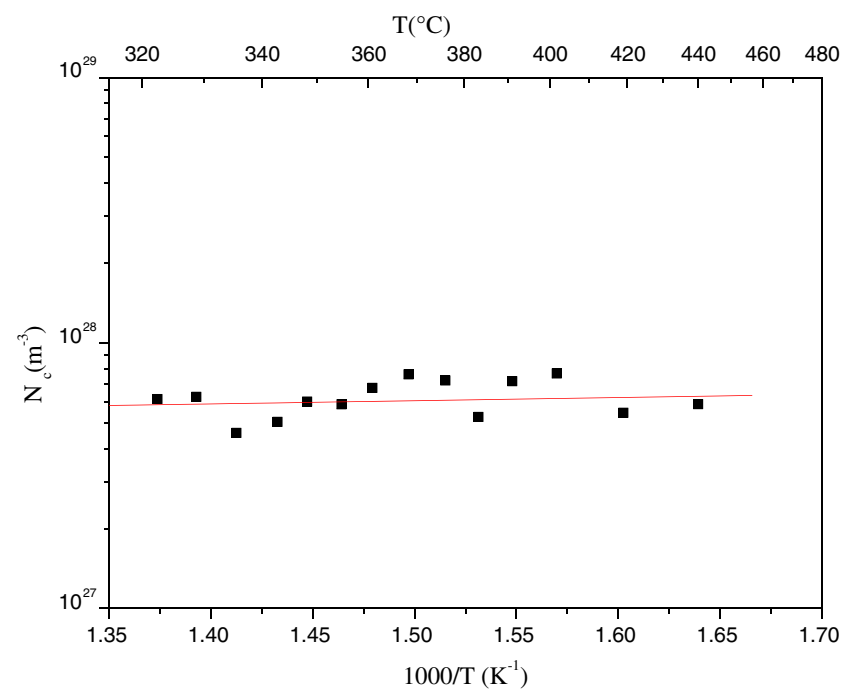

Fig. 15 Variation of the effective charge carrier $N_{\mathrm{c}}$ as a function of temperature 


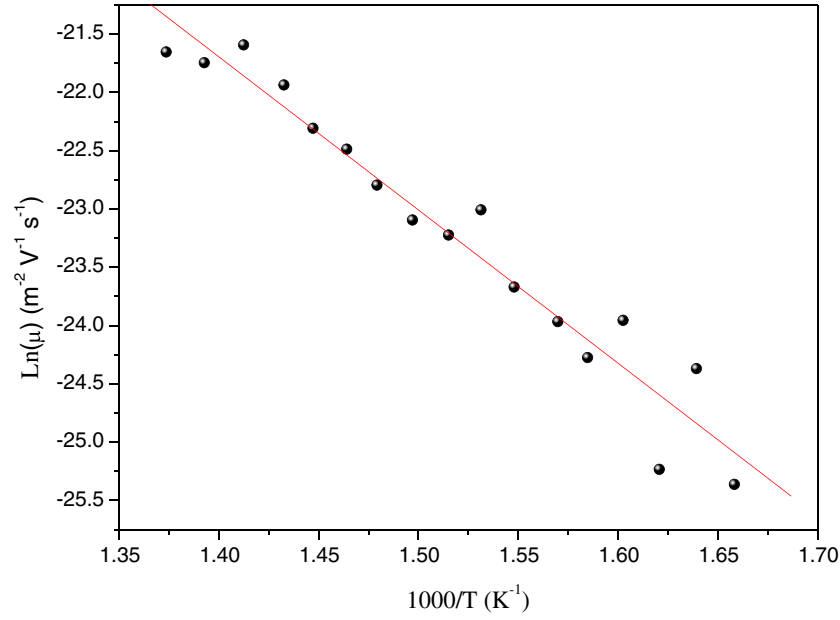

Fig. 16 Temperature dependence of mobility $\mu$

where

$\omega_{\mathrm{e}}=\omega_{0} \exp \left(\frac{S_{\mathrm{m}}}{k}\right)$.

In Eqs. (20) and (21), an effective attempt frequency, $\omega_{\mathrm{e}}$, is introduced by combining the true attempt frequency, $\omega_{0}$, with the enhancement produced by a finite entropy of migration $S$. The migration entropy term, $\exp \left(S_{\mathrm{m}} / k\right)$, has a profound influence on the ion conductivity. The true attempt frequency $\omega_{0}$ is the fundamental vibrational frequency of the mobile ions; an estimation of its value is obtained from the harmonic potential well expression [33]:

$\omega_{0}=\left(\frac{E_{\mu}}{2 m r_{\mathrm{h}}^{2}}\right)^{1 / 2}$

where $m$ is the mass of the mobile ion. The value of migration entropy obtained from $\omega_{\mathrm{e}} / \omega_{0}$ is found to be $S_{\mathrm{m}} / k=6.55$.

\section{Dielectric study}

The measured impedance data are used to calculate the imaginary $\left(\varepsilon^{\prime \prime}\right)$ part of the complex dielectric permittivity as

$\varepsilon^{*}=\frac{1}{i \omega C_{0} Z^{*}}$

where $Z^{*}$ is the complex impedance; $C_{0}=\frac{\varepsilon_{0}}{S e}, S$ and $e$ being the area and the thickness of the sample, respectively; and $\varepsilon_{0}$ is the permittivity of the vacuum. The angular frequency dependence of the real and imaginary parts, $\varepsilon^{\prime}$ and $\varepsilon^{\prime \prime}$, of complex dielectric permittivity $\varepsilon^{*}$ at the same temperatures is presented in Figs. 17 and 18. One observes that $\varepsilon^{\prime}$ approaches a limiting constant value, $\varepsilon_{\infty}^{\prime}(\omega)$, at high frequencies, which can be interpreted as a result of rapid polarization processes with no

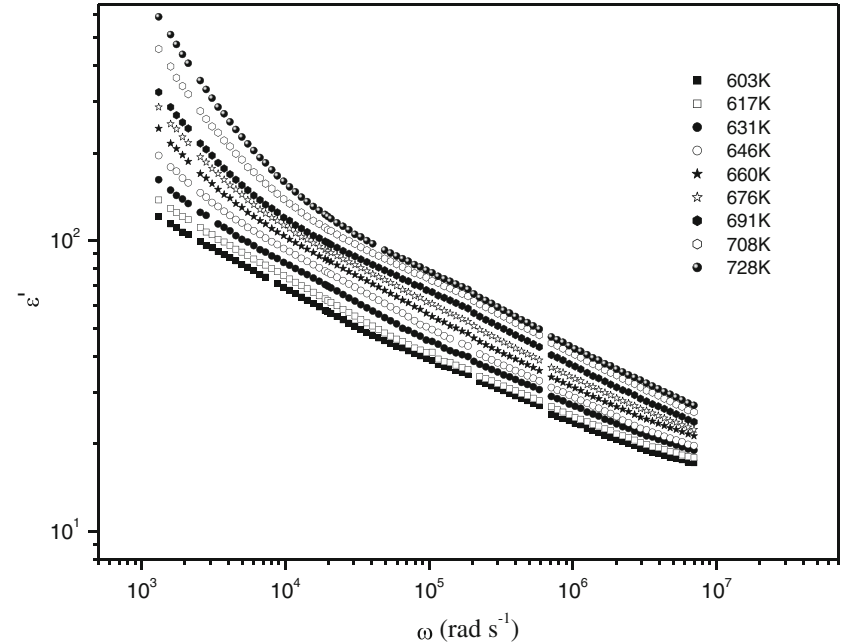

Fig. 17 Angular frequency dependence of the real part $\varepsilon^{\prime}$ of the permittivity for the $\mathrm{K}_{2} \mathrm{NiP}_{2} \mathrm{O}_{7}$ compound at different temperatures

ionic motion contribution because the frequency is too high and the ions can only oscillate without reaching the sampleelectrode interface. At lower frequencies, the $\varepsilon^{\prime}$ values increase with decreasing frequency with a rapid rise at high temperatures. The rise of $\varepsilon^{\prime}$ is due to the sample-electrode interface polarization. The presence of a tail in the complex impedance plan representation confirms that electrode polarization is responsible for the increase of $\varepsilon^{\prime}$ at low frequency and high temperature.

The variation of the imaginary part of the permittivity with frequency shows that conduction losses predominate at lower frequencies, and hence, at all temperatures the imaginary part of the permittivity $\varepsilon^{\prime \prime}$ shows $1 / \omega$ dependence on angular frequency. Also, $\varepsilon^{\prime \prime}$ increases with increasing temperature, and the dielectric loss peak has not been observed. The common method of getting dielectric loss peak in solid electrolytes

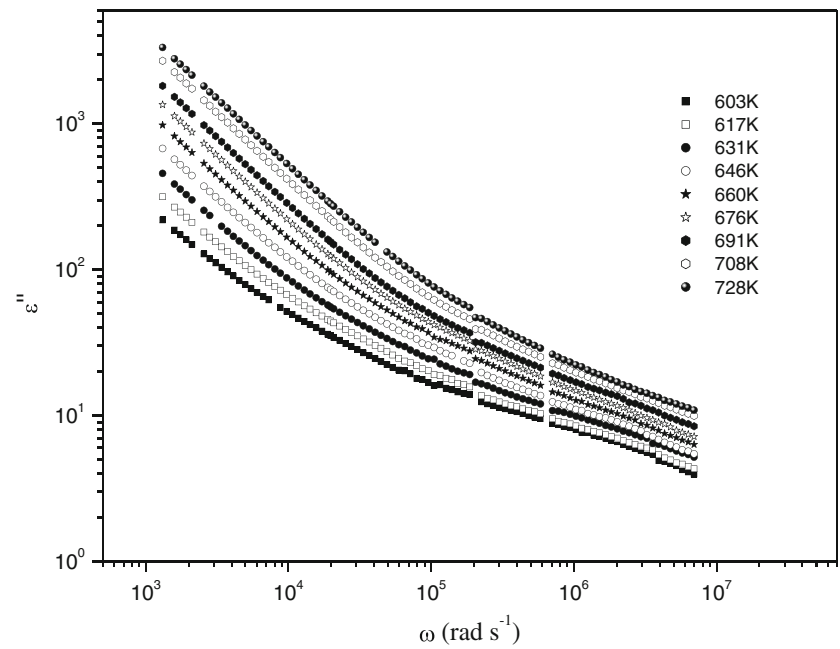

Fig. 18 Variation of the imaginary part of dielectric constant versus frequency 
is through separating dc conductivity from the total conductivity $\sigma(\omega)$. However, in ionically conducting materials, at low frequencies there is an unavoidable electrode polarization effect and the dielectric constant is rather high. This often yields a large experimental error during the separation of $\mathrm{dc}$ conductivity from the total conductivity [34].

An analysis of the ion conductivity relaxation process in polycrystalline has been undertaken in the complex modulus $M^{*}$ formalism. This formalism $\left(M^{*}=1 / \varepsilon^{*}=i \omega C_{0} Z^{*}\right.$, where $C_{0}$ is the vacuum capacitance of the cell) is useful in determining charge carrier parameters such as the conductivity relaxation time [35]. Figure 7 (inset) shows a typical variation of the imaginary part of complex modulus at $728 \mathrm{~K}$. The spectrum shows a good conformity between experimental and fitted data, which implies that the used equivalent circuit describes well the electrical behavior of the sample.

The maximum of the well-defined peak of modulus curves corresponds to the modulus relaxation frequency $f_{\mathrm{m}}$ which is linked to the bulk relaxation frequency $f_{\mathrm{p}}$ as [36]

$f_{\mathrm{p}}=r \cdot f_{\mathrm{m}}$

where $r$ is the relaxation ratio defined as

$r=\frac{\varepsilon_{\mathrm{s}}^{\prime}}{\varepsilon_{\infty}^{\prime}}$.

The variation of the bulk relaxation frequency $f_{\mathrm{p}}$ with temperature follows the Arrhenius relation $f_{\mathrm{p}}=f_{0} \exp \left(-E_{\mathrm{p}} /\right.$ $k T)$, where $f_{0}$ is the frequency at infinite temperature and $E_{\mathrm{p}}$ is the activation energy (Fig. 14).

The activation energy extracted from the slope of the plot is $1.06 \pm 0.05 \mathrm{eV}$ which is in the vicinity of $E_{\mathrm{hop}}$ and $E_{\mathrm{dc}}$ values $\left(E_{\mathrm{hop}}=1.07 \pm 0.05 \mathrm{eV}, E_{\mathrm{dc}}=1 \pm 0.05 \mathrm{eV}\right)$, suggesting that the relaxation process and the electrical conductivity are ascribed to the same effect.

\section{Thermodynamic parameters}

From the Eyring theory, the relaxation time is related to the free energy by the following expression $[37,38]$ :

$\tau=(h / k T) \exp (\Delta F / R T)$

where $\Delta F$ is the Gibbs free energy of activation for dipole relaxation during rotation, $R$ is the gas constant, $k$ is Boltzmann's constant, and $h$ is Planck's constant.

Further, $\Delta F$ is related to the enthalpy of activation $\Delta H$ and entropy activation $\Delta S$ by the relation

$\Delta F=\Delta H-T \Delta S$.

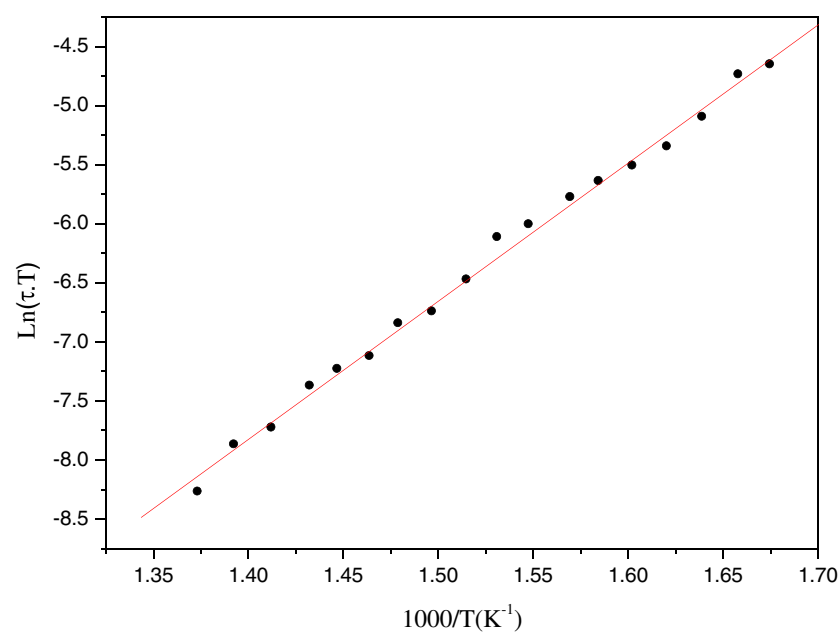

Fig. 19 The temperature dependence of $\operatorname{Ln}(T \cdot \tau)$

This can be expressed as

$\tau=\frac{h}{k T} \exp \left(\frac{\Delta H}{R T}\right) \exp \left(-\frac{\Delta S}{R}\right)$.

The temperature dependence of $\operatorname{Ln}(T \cdot \tau)$ (Fig. 19) shows a straight line whose intercept and slope respectively give the entropy and enthalpy of the system. The resulting values are $\Delta H=23.13 \mathrm{kcal} \mathrm{mol}^{-1}$ and $\Delta S / k=-1.05$. The negative value of $\Delta S$ may be due to the existence of dipole-dipole interactions and suggests that the molecules are more nearly aligned with each other in the activated state [39].

\section{Conclusion}

The ac conductivity and dielectric behavior of the $\mathrm{K}_{2} \mathrm{NiP}_{2} \mathrm{O}_{7}$ compound have been studied as a function of temperature and frequency. The ac conductivity showed a variation with angular frequency, and it was found to obey the augmented Jonscher power law at different temperatures. The electrical transport is due to the $\mathrm{K}^{+}$cation hopping along the $[0,0,1]$ lattices located between $\mathrm{P}_{2} \mathrm{O}_{7}$ groups and $\mathrm{NiO}_{6}$ octahedra. The concentration of the charge carrier is independent of temperature; a comparison between the number density of $\mathrm{K}$ sites and the number of effective charge carriers shows that $57.65 \%$ of the $\mathrm{K}^{+}$ions are responsible for the conduction in this material. Thermodynamic parameters such as entropy, enthalpy of activation for the dipolar orientation, and migration entropy have been calculated. The $\mathrm{K}_{2} \mathrm{NiP}_{2} \mathrm{O}_{7}$ sample is characterized by high migration entropy $(S / k=6.55)$. 
Open Access This article is distributed under the terms of the Creative Commons Attribution License which permits any use, distribution, and reproduction in any medium, provided the original author(s) and the source are credited.

\section{References}

1. Shepelev YF, Petrova MA, Novikova AS, Lapshin AE (2002) Glas Phys Chem 28:317

2. El Maadi A, Bennazha J, Réau JM, Boukhari A, Holt EM (2003) Mater Res Bull 38:865

3. Hatwar LR, Wankhhede SP, Moharil SV (2012) Int J Knowl Eng 3:160

4. Faggiani R, Calvo C (1976) Can J Chem 54:3319

5. Maspoch D, Ruiz-Molina D, Veciana J (2007) Chem Soc Rev 36:770

6. Whangbo MH, Dai D, Koo HJ (2004) Dalton Trans 19:3019

7. Millet JMM, Vedrine JC (1991) Appl Catal 76:209

8. Uebou Y, Okada S, Egashira M, Yamaki JI (2002) Solid State Ionics 148:323

9. Zhou H, Upreti S, Chernova NA, Hautier G, Ceder G, Whittingham MS (2011) Chem Mater 23:293

10. Barpanda P, Nishimura SI, Yamada A (2012) Adv Energy Mater 2:841

11. El Maadi A, Boukhari A, Holt EM (1995) Chem Crystallogr 25:531

12. El Maadi A, Matthiesen CL, Ershadi P, Baker J, Herron DM, Holt EM (2003) Chem Crystallogr 33:757

13. Massiot D, Theile H, Germanius A (1994) Bruker Rep 140:43

14. Mahesh MJ, Gopalakrishna GS, Ashamanjari KG (2007) Mater Sci Semicond Process 10:117

15. Idrissi MS, Rghioui L, Nejjar R, Benarafa L, Saidi Idrissi M, Lorriaux A, Wallart F (2004) Spectrochim Acta A 60:2043
16. Clavier N, Wallez G, Dacheux N, Bregiroux D, Quarton M, Beaunier P (2008) Solid State Chem 181:3352

17. V. Campomar (1990) NMR magic angle rotation of ${ }^{31} \mathrm{P}$ : application to the study of some phosphates. Thesis, Paris VI

18. Hlel F, Kamoun S, Guidara K (2006) Z Naturforsch 61:375

19. Emma EM, Anthony RW (2010) Solid State Chem 183:624

20. Louati B, Guidara K (2011) Ionics 17:633

21. Dyre JC, Schrøder TB (2000) Rev Mod Phys 72:873

22. Rivera A, León C, Sanz J, Santamaria J, Moyniham CT, Ngai KL (2002) Phys Rev B 65:224302

23. Nowick AS, Lim BS (2001) Phys Rev B 63:184115

24. Mocdonald JR (1997) Non Cryst Solids 210:70

25. León C, Rivera A, Varez A, Sanz J, Santamaria J, Ngai KL (2001) Phys Rev Lett 86:1279

26. Megdiche M, Mahmoud H, Louati B, Hlel F, Guidara K (2010) Ionics 16:655

27. Louati B, Hlel F, Guidara K (2009) Alloys Compd 486:299

28. Roling B, Happe A, Funke K, Ingram MD (1997) Phys Rev Lett 78:2160

29. Sidebottom DL (1999) Phys Rev Lett $82: 3653$

30. Schroder TB, Dyre JC (2000) Phys Rev Lett 84:310

31. Mott NF, Davis EA (1979) Electronic processes in non-crystalline materials. Oxford University Press, Oxford

32. Uvarov NF, Hairetdinov EF, Réau JM, Bobe JM, Sénégas J, Poulain M (1994) Solid State Ionics 74:195

33. Almond DP, West AR (1987) Solid State Ionics 74:27

34. Louati B, Guidara K, Gargouri M (2009) Alloys Compd 472:347

35. Louati B, Guidara K (2012) Mater Sci Eng B 177:838

36. Cao W, Gerhardt R (1990) Solid State Ionics 42:213

37. Eyring H (1936) Chem Phys 4:283

38. Hashem HA, Abouelhassan S (2005) Chin J of Phys 43:955

39. Sarode AV, Kumbharkhane AC (2011) Mol Liq 164:226 